\title{
Assessing Operability on Berthed Ships. Common Approaches, Present and Future Lines
}

\author{
Rafael Molina-Sanchez ${ }^{1}{ }^{10}$, Álvaro Campos ${ }^{1, *}$, Marta de Alfonso ${ }^{2}$, Francisco J. de los Santos ${ }^{3}$, \\ Pablo Rodríguez-Rubio ${ }^{3}$, Susana Pérez-Rubio ${ }^{2}$, Alberto Camarero-Orive ${ }^{1}$ and \\ Enrique Álvarez-Fanjul ${ }^{2}$ \\ 1 Universidad Politécnica de Madrid (UPM), 28040 Madrid, Spain; rafael.molina@upm.es (R.M.-S.); \\ alberto.camarero@upm.es (A.C.-O.) \\ 2 Organismo Público de Puertos del Estado (OPPE), 28042 Madrid, Spain; mar@puertos.es (M.d.A.); \\ sperez@puertos.es (S.P.-R.); enrique@puertos.es (E.Á.-F.) \\ 3 Autoridad Portuaria Bahía de Algeciras (APBA), 11207 Algeciras, Spain; fsantos@apba.es (F.J.d.l.S.); \\ prodriguez.ate@apba.es (P.R.-R.) \\ * Correspondence: alvaro.campos@upm.es; Tel.: +34-630-66-75-72
}

Received: 11 March 2020; Accepted: 2 April 2020; Published: 4 April 2020

\begin{abstract}
The revenue of a ship company, a terminal, a port and even the whole logistic chain largely depends on the performance of (un)loading operations inside port areas. However, they are conditioned by met-ocean agents that exert stresses on fixed structures, berthed ships and mooring systems that can affect the comfort, productivity and safety of the operations. Under extreme conditions, operations may be interrupted, producing periods of inactivity, economic losses and even jeopardizing the terminal's reliability. Therefore, it is crucial to develop strategies for characterizing and predicting operability in docks and anchorages. The present paper aims to assess the main approaches up to date to address the operability on berthed ships and to explore present and future strategies. To accomplish this, main factors affecting the operability are reviewed and different methodologies for the characterization and calculation of operability are detailed, together with some results regarding the perception of vulnerability from the Spanish port community. Rather than aiming for generic mono-parametric thresholds, the results highlight the need for addressing this challenge in a specific way for each dock and anchorage, broadening field monitoring and considering the varied peculiarities and the specific perception and experience of main port's actors.
\end{abstract}

Keywords: operability; thresholds; downtimes; berthed ships; ship movements; customization; decision-making; port management; user experience

\section{Introduction}

The economy of scale has fostered the increase in ship's dimensions, demanding longer and deeper docking facilities. This implies that new ports often need to be constructed in areas exposed to met-ocean agents ${ }^{1}$, beyond the shelter of natural bays and headlands. In such conditions, infrastructural integrity regarding the port's sheltering structures (ULS, Ultimate Limit State or SLS, Serviceability Limit State) is the priority during the design stage. However, during this stage it is also crucial to estimate potential operational downtimes caused by environmental factors within the useful life in

1 Term referred to the combination of meteorological and physical oceanography forcing agents, such as wind and water level fluctuations. A complete review is provided within the concept of physical environment agents from the Spanish Recommendations for Maritime Infrastructures, see ROM 0.0, 2001 [1] 
order to justify the infrastructural investment and also in order to optimize the port's management. This is due to the fact that the port's revenue is largely derived from the performance of (un)loading activities, which also have an impact in the logistic chain as a whole.

The aim of berthing and mooring operations is to allow cargo to be handled in conditions of functional safety and operational reliability. Short- and long-term water-level oscillations within a dock might compromise the efficiency and safety of operations performed at berths and the reliability and durability of their structural elements. Wave action, together with other forcing met-ocean agents such as wind, can provoke the excessive movement of moored ships and, consequently, economic losses due to decreased operational performance. Thus, both from the design and the port's management perspective, it is necessary to address the probability of exceedance of operational thresholds on each Area of Operational Interest ${ }^{2}$ (AOI, see Molina et al. 2017, [2] and Gómez and Molina et al. 2018, [3]), to estimate how the performance and safety of each operation may be compromised, and to characterize the number and duration of downtimes (Sierra et al. 2017, [4], Camus et al., 2019 [5], Gracia et al., 2019 [6], Campos et al., 2019 [7]).

The state of the art of a ship's operability is mainly focused on their seakeeping and maneuverability (Newman, 1978 [8], Lloyd, 1989 [9], Mata-Álvarez-Santullano and Souto-Iglesias, 2014 [10], Manderbacka et al., 2019 [11]), on the comfort and safety of people on board (Sariöz and Sariöz, 2005 [12], Tezdogan et al., 2014 [13]) or on the design and analysis of singular maneuvers (Cabrerizo et al,. 2012 [14], 2018 [15], Acero et al., 2016 [16]). Most studies on vessels' operability have so far been developed under unconstrained hypothesis and, thus, their main objective is to identify excessive movements during navigation and open anchorage. On the contrary, studies on operability on berthed ships are less common. Most of them are summarized in three references: the Working Group 24 from PIANC (Permanent International Association of Navigation Congresses, see PIANC, 1995 [17]), ROM Program (Spanish Recommendations for Maritime Infrastructures, see ROM 2.0, 2011 [18]), and the Working Group 115 from PIANC (see PIANC, 2012 [19]). These references attempt to relate operability to the maximum allowable movements of a vessel and also to the wave agitation that provokes these movements. To accomplish this, different thresholds are proposed for various vessel typologies based on numerical and physical modeling and, also, on a scarce field monitoring experience. In Goedhart (2010) [20] a methodological approach for estimating the efficiency of the operations is proposed, considering the duration of the (un)loading, the admissible movements of the ship and the accumulated delays due to downtimes.

Nevertheless, despite being of high interest to the Port System, the aforementioned thresholds are of limited applicability for several reasons. The mono-parametric approach is a simplification of a multidimensional dynamic problem involving the interaction of stochastic met-ocean agents, a semi-coerced floating body with 6 Degrees of Freedom $(\mathrm{DoF})$, the structural infrastructure, the cargo, the handling means and the human factor (regarding the skills and the perception of vulnerability from the operator). Furthermore, so far it is not possible to address a probabilistic characterization of the performance of each operation, as no references have been identified providing local wave agitation records, the response of the ship or other factors of relevance, that will be described within the present document. Indeed, rather than establishing standard operating thresholds for such a complex and quite unique problem at each dock, an alternative approach would consist of facilitating threshold-based decision-making tools for the actual operators in order to allow them to manage each particular challenge according to their experience and needs. To accomplish this, an adequate characterization of the met-ocean agents at each $\mathrm{AOI}$ is needed, together with the onsite monitoring of the movements of the vessel during operations.

2 The concept of AOIs was introduced by Molina et al. (2017) and Gómez and Molina et al. (2018) [3] to refer to "port spaces with the same functional activity, which shares infrastructure typologies, handling means, land uses, etc., and are subjected uniformly to agents of the physical environment". It is an interpretation, from an operational perspective, of the concept of the "subset of the structure" introduced in ROM 0.0 (2001) [1] 
This article is aimed at reviewing, in Section 2, the main factors that need to be considered in the evaluation of the operability of berthed ships, highlighting the limitations currently faced by the different strategies applied for its estimation: physical modeling, numerical modeling and field monitoring. Section 3 summarizes common methodologies for its characterization, together with new approaches encouraged in the Spanish Port System by the OPPE (Organismo Público de Puertos del Estado, the Spanish public organism in charge of managing state-owned ports). In addition, thanks to the customizable web tools already implemented by the OPPE, a set of user-based operative thresholds from the Spanish Port System was surveyed and analyzed. Based on all the information discussed within the paper, Section 4 offers main conclusions, including a final scheme summarizing a new conceptual approach toward the operability assessment on berthed ships.

\section{Factors Affecting the Operability of Berthed Ships}

According to Bruun (1990) [21] and Gaythwaite (1990) [22] different forcing agents can interact with a berthed ship and its terminal (see Figure 1): atmospherics, oscillating, currents and use and exploitation factors.

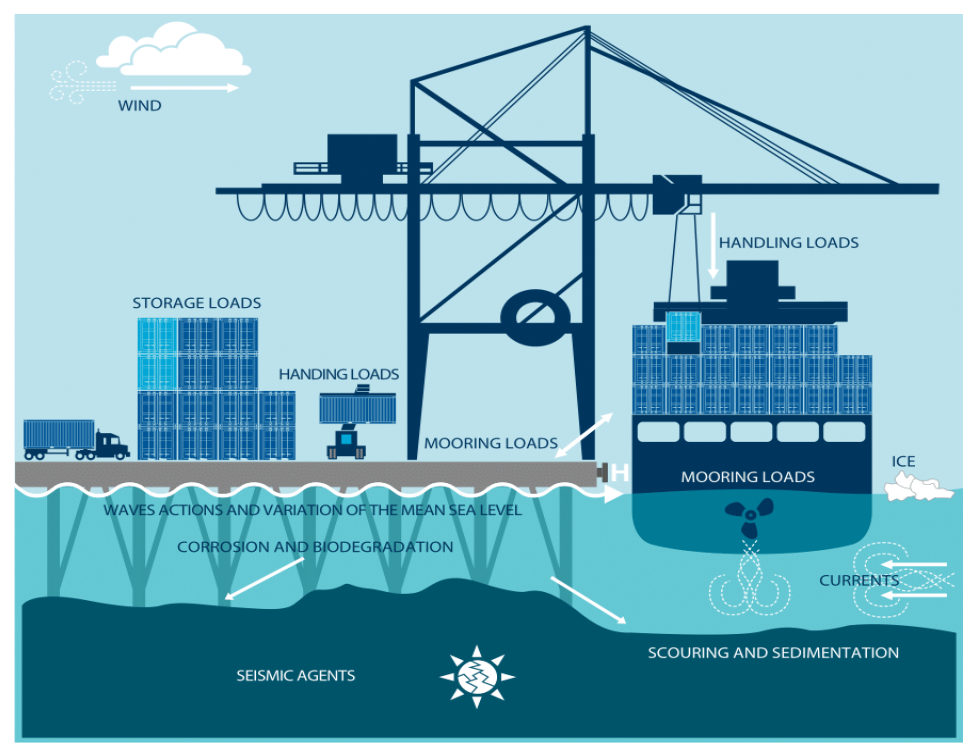

Figure 1. General scheme of the predominant forcing agents interacting with a berthed ship and the terminal elements. Reproduced from Gómez and Molina et al. (2018) [3].

The efficiency of (un)loading operations at docks, as well as other ship-based operations such as bunkering, can be assumed to be mainly associated with the dynamic response of the ship. An exception would be the occurrence of adverse weather conditions or rough situations not affecting the ship stability, such as the presence of smoke, thick fog or others. The dynamic response of the ship includes ship motion as well as the associated accelerations and velocities. This response depends basically:

- On factors related to the ship itself and the port infrastructure

- On the forcing met-ocean agents that constrain and interact with the ship and the port infrastructure.

As it is further expounded in Section 3.5, the operator's perception and skills also plays an important role, besides all these factors, in the present and the near future concept of operability. Note that, for example, not every crane operator has the same perception of vulnerability against wind action, as well as the fact that not every crane is designed to be under the same wind limitations. 


\subsection{Dynamic Response of the Ship}

Due to the high number of variables, their great heterogeneity and the complexity of the processes involved, the precise characterization and prediction of the operability in a certain dock or anchorage is not an easy task. However, the progressive (not Boolean) sensitivity of (un)loading operations (or other ship-based operations such as bunkering) can be directly associated, in most cases, with the dynamic response of the vessel. The dynamic response of the vessel is usually referred to as ship motion, although it is important to take into account that the accelerations and velocities of these movements are also capable of introducing limiting operative conditions. The dynamic response of the ship is likely to reduce the performance of the operation and the quality of the service, especially if the movements are amplified as a result of the interaction with the forcing agents. For example, in a container terminal, the movements of the container ship exceeding certain limits will force the operator to adjust the position of the handling means, losing time and reducing productivity. If these movements exceed certain limits, the safety of the operation might also be compromised, as damage to the vessel, moorings, fenders, infrastructure, handling means, etc., could also happen. Nevertheless, there is a noticeable uncertainty in the establishment of these limits and their linkage to operability and operational safety. In order to analyze the downtime process, PIANC (1995) [17] proposes to move from a full operation region to a full downtime region following four stages according to the scheme in Figure 2:

- Between points A and B, small movements of the ship caused by met-ocean forcing agents and cargo handling do not alter productivity.

- Once a certain threshold is exceeded, a progressive decrease in efficiency between points B and C is initiated. In this scheme, the decrease is assumed to be linearly related to the ship movement.

- When the ship movements make the operation unsafe (point C), the (un)loading operations are stopped in order to prevent accidents.

- Finally, point $\mathrm{D}$ represents the limit mooring state: once it is reached the ship must leave the dock to prevent the rupture of fenders, bollards, mooring lines and the damage of the infrastructure and ship' hull.

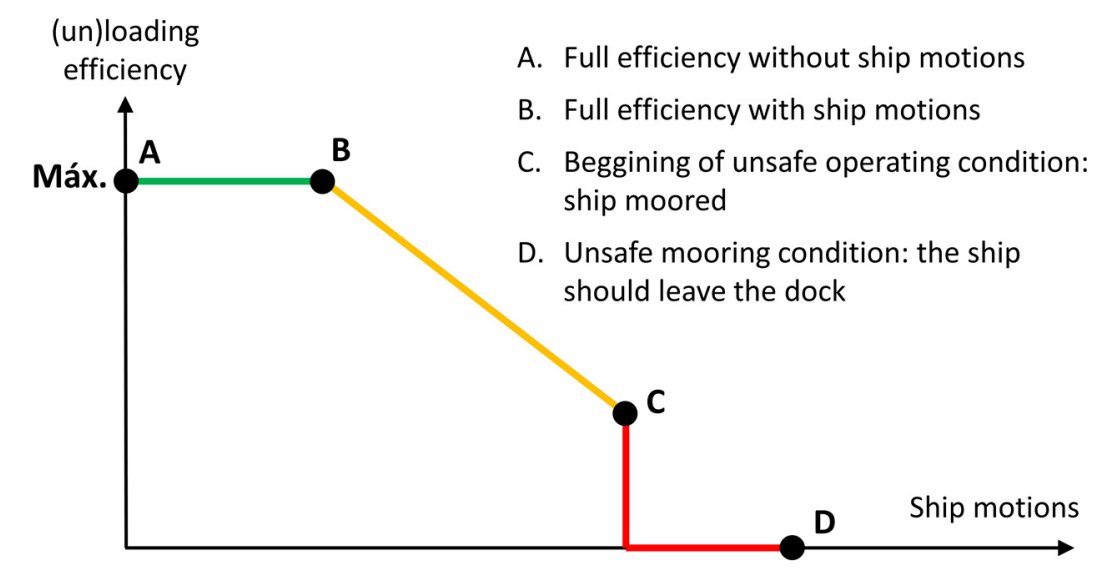

Figure 2. Relation between cargo handling efficiency and ship motions. Adapted from PIANC (1995) [17].

The ship motions, in response to the forces acting on it, are a combination of translation and rotation movements in 6 DoF: heave, sway, surge, yaw, pitch and roll. Some of these movements are more dangerous than others, depending on the type of vessel and operation. For example, pitching is dangerous during shipping and unshipping of vehicles in Ro/Ro vessels, while it will hardly affect the operation of a VLCC (Very Large Crude Carrier). For ships moored in an offshore terminal, such as a Monobuoy (a single-buoy mooring facility), movements in the vertical plane (rolling, pitching and 
heaving) will be the critical ones in the operations (Thoresen, 2010 [23]). In (un)loading maneuvers for container ships, it has been shown that surging is the most undesirable movement. This was identified from the development of the first container's terminals (Slinn, 1979 [24]) and it is still valid nowadays (Moes and Terblanche, 2010 [25]). In general, it could be stated that the most dangerous movements are the ones on the horizontal plane (surging, swaying and yawing), since they might be able to break the mooring lines or the bollards of the pier. Therefore, from the point of view of operational safety, these movements need to be minimized, as well as avoiding the possibility of creating a resonant system.

\subsection{Factors from the Ship Itself and the Port Infrastructure}

Since the main purpose of the port infrastructure is to enable the transfer of cargo between the ship and the dock, it is necessary to restrict the movements of the vessel, in this way limiting the stresses on the dock's infrastructure and on the vessel itself. This is the purpose of mooring lines, which are attached to bollards or, occasionally, to quick connection mechanisms. They are particularly effective in preventing surging, swaying and yawing. The constraint of movements from mooring lines results in a change in the periods of oscillation with respect to the unconstrained condition of the vessel.

Fenders also play a key role in controlling the movements of the ship, as they are generally greater when vessels are not in contact with the system of fenders. The combination between mooring tension and fenders limits the ship motions (Rosa-Santos et al., 2014 [26]) and modifies its frequency, typically by increasing the response frequencies together with the tension to which the system is subjected.

The layout, number and type of mooring lines, the types of winches or the number and type of fenders are other elements that affect the movements of the ship.

The typology of the port sheltering infrastructure and docks (which is related to the reflection coefficient regarding wave action), the geometric configuration of the Port and its location also influence the ship motion, by conditioning the interaction with the met-ocean forcing agents.

The geometric and inertial configuration of each vessel also plays a fundamental role in the dynamic response of the ship. Their inertia is dependent on characteristics such as its length, beam draft or air draught. The size of the vessel highly influences the response against free surface oscillations. Note that most references about the operability of berthed ships are only focused on the relation between wave amplitude and ship motion. However, this simplified approach leaves out the frequency domain of the forcing met-ocean agents, which is indeed the one associated with the dynamic response of the ship. For example, when considering just wave action on a 2D approach, wave height regarding ship motion offers scarce information when not combined with wave period, as shown in Figure 3. Therefore, the amplitude of ship motions is determined by the magnitude and frequency of the forcing agents, as well as by the ship's mass and the prestressing of the mooring system. In general, for the same mooring strain, larger vessels have a lower range of motion than small vessels. Note that when a forcing agent has the same frequency (or a harmonic of the same frequency) as one of the 6 DoF of the moored ship, the movement will be amplified.

The type of cargo good and its arrangement within the ship are also important, especially taking into account the different stages during the (un)loading operation. As an example, a fully loaded container ship presents a greater windage area, being more likely to be affected by wind than a container ship without cargo. Also, as shown in Figure 4, the type of ship and cargo highly influence the allowable limit of motion during operations. Due to the vulnerability of the connection with (dis)embarking gateways and the high risk involving human lives, in this case cruise ships present the most restrictive operative limits for most of the 6 DoF.

Finally, despite not necessarily being linked to ship motion, the handling means are a key factor in the operability of a terminal. There are several types of cranes (floating cranes, bulk-handling cranes, gantry cranes, hammerhead cranes, tower cranes ... ) which interact differently with the handling goods and which present a different vulnerability against wind and against the ship motion. However, as stated before, the operator's perception and skills play a key role in the efficiency and in the limit of operative conditions. 


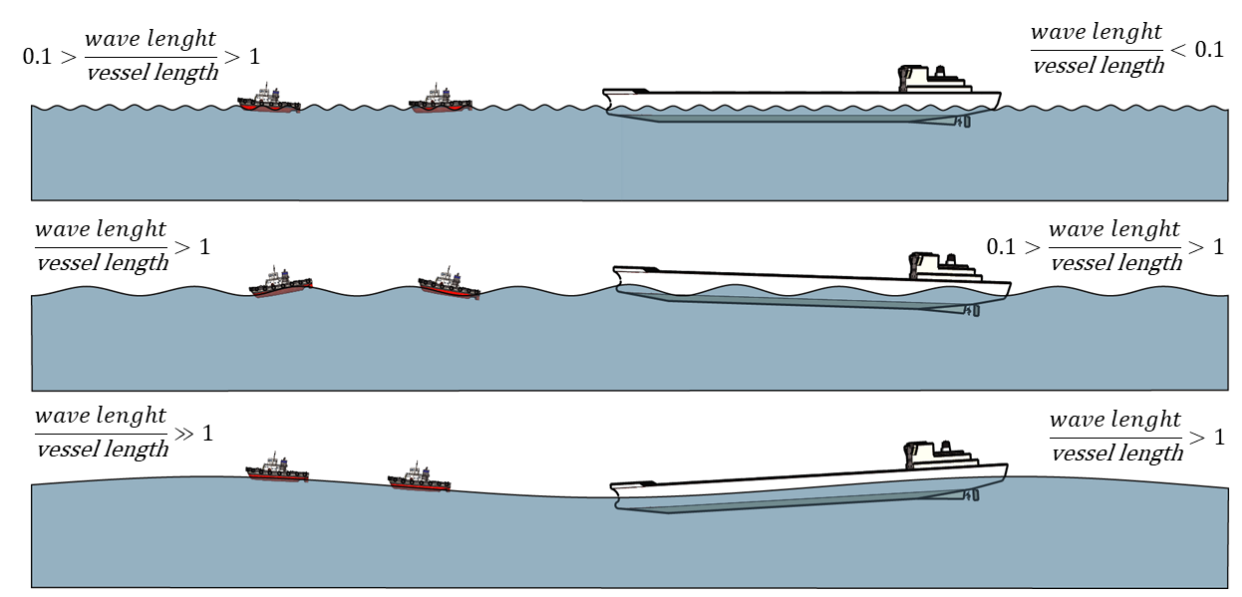

Figure 3. Influence of wave period on ship movements for different types of vessels and the same wave height. Adapted from Molina (2015) [27].

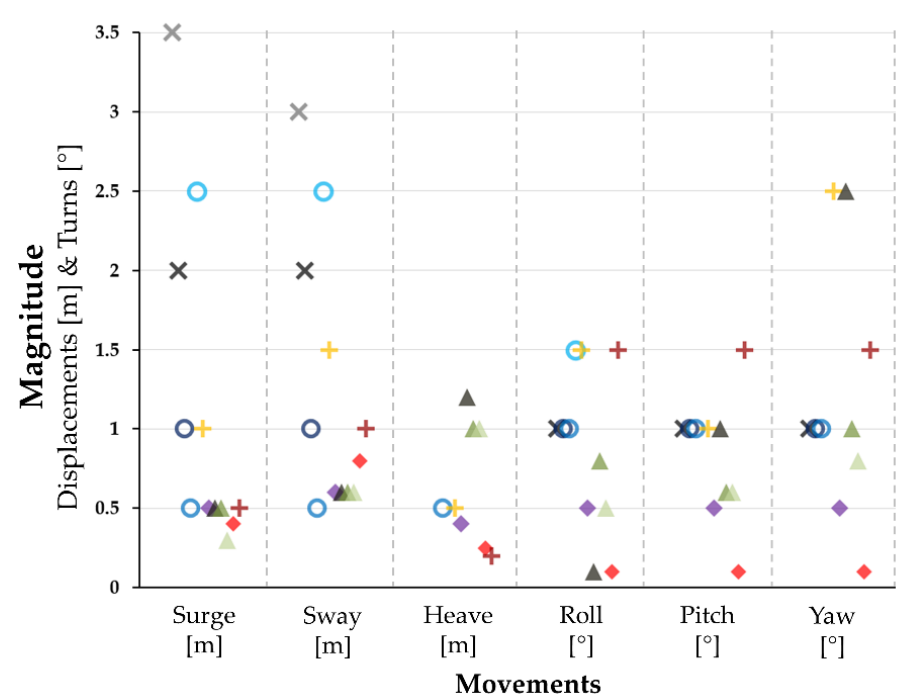

Crude oil tankers

$\times$ Continuous: articulated arm $\underline{\text { Gas carriers }}$

X Continuous: articulated arm Bulkcarriers and multipurpose

O Discontinuous lift: load

Discontinuous head: download +

Continuous: discharge

Continuous: load

General cargo

+ Discontinuous: Lifting

Container ships

Discontinuous: Lifting

$\underline{\text { Ro-Ro and Ferries (vehicles) }}$

$\Delta$ Rolling vehicles: lateral ramp

$\triangle$ Rolling vehicles: ramp $3 / 4$

Rolling vehicles: bow/stern ramp

Ferries and cruise ships

- Embarking/Disembarking gateway

Fishing ships

+ Discontinuous: Lifting

Figure 4. Review of operational thresholds for different ship types, considering the handling mean's system. Own elaboration, based on the thresholds from ROM 2.0 (2011) [18].

\subsection{Forcing Met-Ocean Agents}

As mentioned, operability depends on factors beyond the control of the operation: the forcing met-ocean agents. In the following, the main ones and their influence in the (un)loading operation (or other ship-based operations such as bunkering) are detailed: wind, free surface oscillations and currents:

Wind load can be divided into a quasi-static (mean) component and a variable component (gust). Depending on the wind direction in relation to the vessel orientation, the average wind load can also cause a quasi-static inclination of the vessel which usually does not involve any serious interruption of operations. However, a gust high enough to separate the vessel from the fenders, reducing friction with them, could lead to larger movements of the vessel, especially surging. Fluctuations in wind speed and direction can cause oscillating movements of the vessel, potentially reducing the efficiency of a terminal.

The calculation of the forces induced by wind involves the estimation of a friction coefficient which depends, among other variables, on the shape of the vessel (including the superstructure and cargo) and the angle of the wind relative to the vessel orientation. Ships with large air draughts are particularly sensitive to wind loads. However, wind pressure is not usually a limiting factor regarding 
the vessel, as the (un)loading operations are often affected earlier by cranes' own wind limitations rather than by the ship's movements. Cranes typically stop operating when gust speeds exceed, or are close to, $\mathrm{v}$ [m/s] = 25 (Jensen et al., 1990 [28], PIANC, 2012 [19]).

It should be noted that, in general, wind data are given at a height of $10 \mathrm{~m}$, which is not always suitable for any type of load (CEM, 2005 [29]). There is no onsite information on how the boundary layer is developed inside the AOIs, which hinders the estimation and characterization of the real magnitude of the wind at the height where it interacts with the different elements of the operation. In addition, the weather stations inside ports and terminals are not capable of measuring the gust factor within time spans directly related to the dynamic response of slender structures (cranes), hanging cargo (containers) and ships of different sizes. Indeed, the influence of the gust factor in the safety, efficiency and comfort of operations is not yet addressed in the literature. In this context, the user experience is of high importance, as the mean and maximum values provided by the forecasting models or weather stations are not directly associated with their perception of vulnerability and efficiency within their activities. Focusing on the free surface oscillations, there are four types of prevailing oscillations that significantly participate in the motion of moored vessels: astronomical tide, sea waves, swell waves, and infra-gravitational waves. Waves caused by passing ships (Díaz-Hernández et al., 2018 [30]) can also be included in this group, but their influence on the (un)loading operations is very small compared to the previous ones because they are short-lived and can be controlled, for example, with speed restrictions within the port. However, its influence may be relevant to the integrity of moored small vessels.

The astronomical tide plays an important role in currents and also causes a change in the relative position of the ships with respect to the mooring infrastructure. The variation of the mean level occurs at low speed, and so, it does not significantly affect the operation, although it does affect the position of the fenders and the placement of moorings. It is usually considered as a deterministic mono-parametric variable, taking into account the position of the water level based on the harmonic's local components.

Sea waves (with periods typically from $4 \mathrm{~s}$ to $10 \mathrm{~s}$ ) are generated locally due to wind action and are characterized by relatively short wavelengths and wideband spectral functions. Their height and period are limited by the duration of the gusts and/or the fetch. Sea waves mainly affects small boats, such as fishing vessels and recreational crafts. For large vessels, their influence is much lesser as sea waves have periods usually below the natural period of bulk carriers, container ships or tanker ships.

Swell waves (with periods typically from $8 \mathrm{~s}$ to $25 \mathrm{~s}$ ) are generated in distant places and are, therefore, not dependent on local wind conditions. They are usually characterized by a high directionality and a narrowband spectral function. These types of waves have oscillation periods potentially coincident with those from commercial moored vessels and, thus, are able to mobilize them, especially on a vertical plane (PIANC, 2012 [19]).

Both sea and swell waves can be characterized in the frequency domain by directional wave spectra. In the time domain, usually statistics related to wave height, period and direction within an hourly sea state are provided, which is assumed to be ergodic and stationary. For assessing the motion of a berthed ship due to sea and swell waves, a wave-to-wave analysis needs to be carried out. To accomplish this, either the local agitation time series or the local agitation spectrum needs to be considered. Once the relation between the local agitation spectrum and the real motion spectrum for the 6 DoF of each ship type is known, this "dynamic response catalog" can be used for assessing operability based on such motion criteria as suggested in Moes and Terblanche (2010) [25].

Infra-gravitational or long waves (with periods typically from $30 \mathrm{~s}$ to $300 \mathrm{~s}$ ) can travel as isolated waves or within short wave groups. When they have a period close to the natural period of the dock, they can be amplified and can cause resonance in the port (Bowers, 1977 [31], Bellotti, 2007 [32], González-Marco et al., 2008 [33]). This coupling phenomenon is also manifest in ships. Therefore, although they generally have small amplitudes compared to sea and swell waves (around $\mathrm{H}[\mathrm{m}]=0.1$ ), the infra-gravitational waves can be crucial in the development of horizontal movements of moored vessels, depending on their mass, and the stiffness of the fender and mooring system. In the case of 
resonance events inside ports, the effects on the moored ship may be dominant when the berthing point is close to a nodal point of a stationary wave (Dean and Dalrymple, 1991 [34]). As it is explained in Section 2.4, this kind of free surface oscillation is likely to be filtered out when applying common signal processing algorithms to the free surface records, such as the zero down-crossing method.

Currents within ports are produced by astronomical and meteorological tides, the influence of wind, the discharges of the industry and/or freshwater contributions from rivers. Their forces interacting with moored ships can generate long-period movements and an increase in mooring tension. This depends, among others, on the hull's geometry, draft, current velocity and relative direction of the current (OCIMF, 2008 [35]), as well as on the stiffness of the fender and mooring system.

\subsection{Difficulties for the Characterization of the Factors Affecting the Operability of Berthed Ships}

As a partial conclusion, all of the aforementioned factors and conditions, which must be considered in the design and exploitation of a berthing and mooring infrastructure, show that the boundary conditions on each specific site are quite unique. The predominant external agents vary even inside the same port, as well as the strategies needed to mitigate their effects on the operations. Notice that the interplay and dependencies among the agents also need to be considered. Therefore, rather than facing a generic approach based on broad guidelines, a particularized approach for each dock and anchorage could be more appropriate for a correct assessment of efficiency. The same would be needed for being able to incorporate an operational risk vision (Gómez and Molina et al., 2018 [3]) based on the consequences of downtimes. However, the design and management of berthing and mooring infrastructures is, in most ports, subjected to uncertainties due to the lack of an adequate characterization of the forcing agents at each AOI and of the response of the system.

It is worth noting the formidable effort carried out by the Port System to allow and enhance the characterization of the physical environment in coastal and port areas. For example, the OPPE has led a generational leap in Spain in the prediction scheme thanks to the project SAMOA (Meteorological and Oceanographic Support Systems for the Port Authorities), making possible the increase of spatial resolution in the measure and modeling of main met-ocean variables that can affect port infrastructures and operations. Given the positive experience of this project (Alvarez-Fanjul et al., 2019 [36]), a second phase of implementation took place: the SAMOA2 project (2018-2021), which will allow most Spanish Port Authorities to count on predictions at each AOI, with a sub-metric resolution and time horizons of up to 72h, for waves (Rodríguez et al., 2019 [37]), wind (Terrés-Nicoli et al., 2019 [38]) and currents (Espino et al., 2019 [39]).

However, the information associated with the ship, which is indeed the main actor of the port logistics chain, remains scarce. AIS (Automatic Identification System) records allow for a precise geo-location of vessels, both in transit and moored, but the dynamic behavior when performing the (un)loading operation is still unknown in most cases. There is also little information about how met-ocean agents affect the handling means and the (un)loading operation. For example, semi-automated or automated port terminals store information about the productivity of their operations, but they find limitations when trying to identify the reasons for the deviations in the efficiency objectives of their subsystems. In this sense, the Port Authority Bahía de Algeciras (Spain) has recently awarded an innovation project aimed to link the efficiency of port terminals to the main reasons that are likely to alter it, in which the main strategic line is based on monitoring the dynamic behavior of the fleet during operations (PROAS, Port Risk Optimized Advanced System [40]).

It needs to be outlined that the studies addressing operating limit conditions during (un)loading (Jensen et al., 1990 [28], Smitz 1992³ , PIANC, 1995 [17], D’Hont, 1999 [41], Moes, 20004 , Satoh et al.,

3 Refers to the original contribution of Mr. Herbert Smitz to the WG 24 (PIANC, 1995 [14]) as an internal document.

4 Nonpublished research work directed by Mr. Hans Moes relating other criteria and physical and numerical modelling at the CSIR (Council for Scientific and Industrial Research, South Africa) for contract projects. 
2003 [42], ROM 2.0, 2011 [18], PIANC, 2012 [19] ... ) are of restricted general applicability, as they cannot be directly extrapolated to the entire fleet or to every dock or anchorage. They are mainly based on physical and numerical models and, to a lesser extent, on field data. The information generated, usually in the form of tables or graphs, is of high interest to the Port Community but shows a non-negligible dispersion in the definition of thresholds. As an example, Figure 5 illustrates the differences of permissible movements according to different authors regarding containerized cargo. Notice that this type of cargo has a high degree of standardization of goods, handling means and vessels and, therefore, their conditions are meant to be favorable for setting generic limit thresholds. However, as it can be seen, there is a variation of the permissible movements in relation to the different references, especially for rolling. This can be due to several reasons, such as the variability in the accuracy of the numerical and instrumental sources used to develop the studies or the heterogeneity in the ship's sample, their cargo status, the type of handling means, the operator's skills, etc.

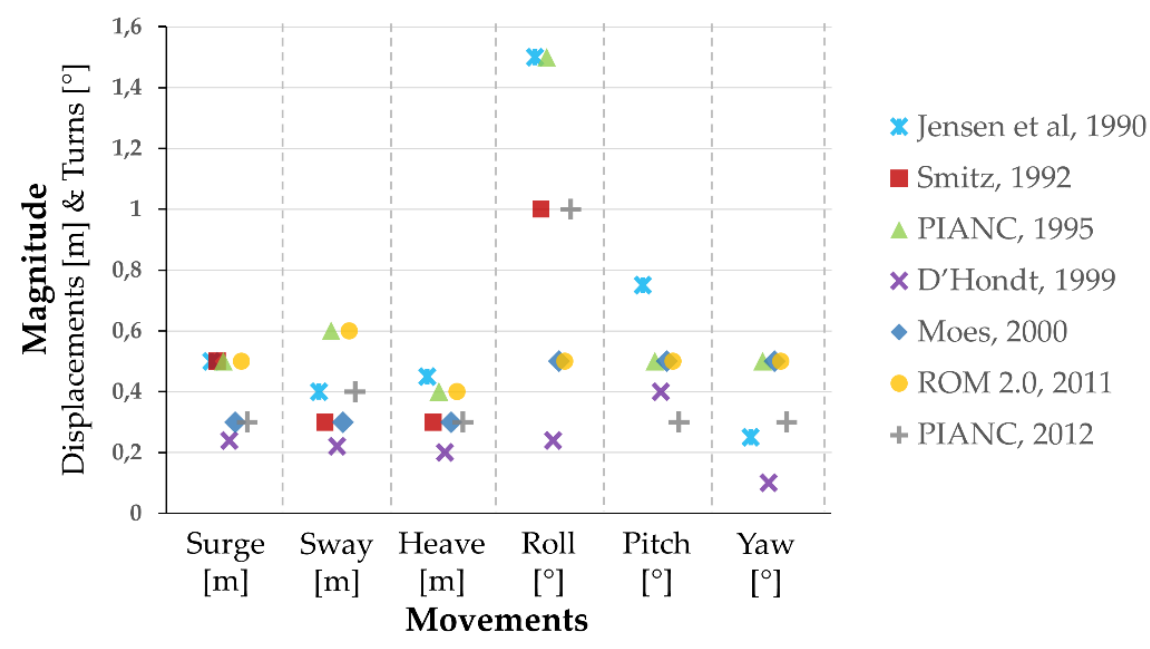

Figure 5. Review of operational thresholds for container ships (ship movements 1990-2012). Own elaboration, based on the thresholds from PIANC (2012) [19] and ROM 2.0 (2011) [18].

Indeed, the definition and characterization of operating limit conditions faces many difficulties (Molina, 2015 [27]), some of which are summarized below:

- In general, limitations are identified in the methodology for characterizing the forcing agents. Being a highly dynamic process, stationery and time-averaged analyses shed limited light on how they affect the ship's movements. Statistical treatments based on zero down-crossing (or up-crossing) analysis, which are common for studying instrumental records of variables such as wave height, need to set a medium level. This means that following this approach the water level is assumed to remains still at a mean level during each operation or, in other words, that the oscillations which are more likely to provoke movements on large vessels (mainly long waves) are filtered out. There are alternative approaches, such as Rainflow methods (Castillo et al. 2012, [43], Gómez et al. 2013, [44]), which allow for the records to be analyzed independently of the reference system by focusing on addressing the number of cycles and their average position in time. Finally, another limitation is assuming that the wave spectrum and the ship's response are known, overlooking coupled relationships with other met-ocean agents.

- Regarding modeling, either physical or numerical, the estimation of the vessel motion and the characterization of the wide casuistic range is a complex exercise since it requires the proper simulation of met-ocean agents, the dynamic response of mooring lines, the vessel itself and its interaction with fenders and handling means. In particular, for physical modeling, the scale for allowing both short and long waves to be simulated in the same model requires large installations. Furthermore, in some cases, passive and active absorption systems are not able to adequately 
absorb low-frequency waves such as spurious waves or resonant waves linked to the natural periods of the experimentation areas (Cabrerizo et al., 2010 [45]). As discussed above, it is also important to include the operator in the modeling process, for example, by means of the Global Operational Simulation methodology presented in Cabrerizo et al. (2012 [14], 2015 [46]). Even if the entire process is successfully reproduced with a high degree of reliability, in order to evaluate the operability, it would still be necessary to simulate the (un)loading operation and to quantify the impact of the movements of the vessel on the performance, safety and quality of the service.

- Regarding the AOIs, there is a deficit in monitoring data from the movements of the vessel and in the onsite characterization of met-ocean agents. This is probably due to the difficulty of installing autonomous, nonintrusive and low-cost monitoring systems, which are three basic principles in the instrumental monitoring design defined in Cabrerizo et al. (2012) [47]. Today, there are numerous techniques that allows for meeting these requirements: laser techniques (Pérez-Arribas et al., 2005 [48]), stereoscopic vision combined with detection of highly reflective objects in infrared light (Johanning et al., 2007 [49], Malheiros et al., 2009 [50], Fujarra et al., 2009 [51]) and GPS-RTK systems combined with gyroscopes and accelerometers installed on board (Figuero et al., 2019 [52]).

At this point, on the one hand, it has been pointed out that there are numerous difficulties in the theoretical and practical definition of what are the allowable movements linked to the efficiency of the (un)loading operation (or other ship-based operations such as bunkering) for the different typologies of docks and vessels inside a particular port. On the other hand, there is currently no extensive field monitoring for developing predictive models in which substantiating the design and management of operations. The latter might be accomplished, for example, by connecting allowable ship movements with the performance levels collected in the PMS (Port Management System), the Port Community System (PCS) or the TOS (Terminal Operating System). Consequently, nowadays the decision to stop an operation is eminently taken by subjective criteria from Port Captaincy, the Port Authority, the ship captain, the terminal operator, or the stevedores. It must be noted that the responsibilities and efficiency objectives of each of the aforementioned groups are not likely to be the same, which means that they are likely to work considering nonconcurrent thresholds. Therefore, it is needed to establish a common perception of the operational vulnerability in the port community. This would allow for shifting to systematic and objective decision-making strategies based on agreed criteria, capable of addressing the particular needs and peculiarities of each operation.

\section{Methodologies for the Characterization and Calculation of the Operability of Berthed Ships}

Operability is defined in ROM 0.0 (2001) [1] as the "complementary value of the overall probability of stoppage in the project phase against the principal stoppage modes, ascribed to all of the stoppage limit states". The operating probability is therefore a multi-dimensional problem for which it is necessary to characterize the operational stoppage modes (and their possible interrelationships), which are defined in ROM 0.0 (2001) [1] as the "cause, reason or motive, whether it be geometrical, physical, mechanical, chemical, biological, etc., for which the structure, or any of its components ${ }^{5}$ has to be taken out of service or its operational level reduced. Once the cause of the stoppage disappears, the structure and its installations become operational again at the level specified in the project". This article is focused on (un)loading operations in docks (extensible other ship-based operations such as bunkering in docks or anchorages) where, as discussed, the stoppage modes are mainly associated with the movements of the vessel. The authors distinguish mainly five methodologies for the definition and calculation of the operability of berthed ships: mono-parametric thresholding, conditioned thresholding, n-dimensional thresholding, inference models and user-oriented thresholding tools.

5 Apart from the structure and its components, other aspects might be added, such as the handling means, the vessels, the auxiliary means, the electrical supply, etc. 


\subsection{Mono-Parametric Thresholding}

The guidelines and recommendations from the Port Sector (Velsink, 1987 [53], ROM Program, 1990 [54], Thoresen, 2010 [23]) associate performance, safety and functionality of operations with mono-parametric thresholds of met-ocean forcing agents. The ROM 0.0 (2001) [1] defines the operational threshold as the "magnitude of a project factor whose excess is significant for the safety, service and exploitation of the work, its elements, and context". This approach assumes the hypothesis that there is a transfer function linking the oscillations of the vessels with a single met-ocean variable, usually wave agitation (see Figure 6).

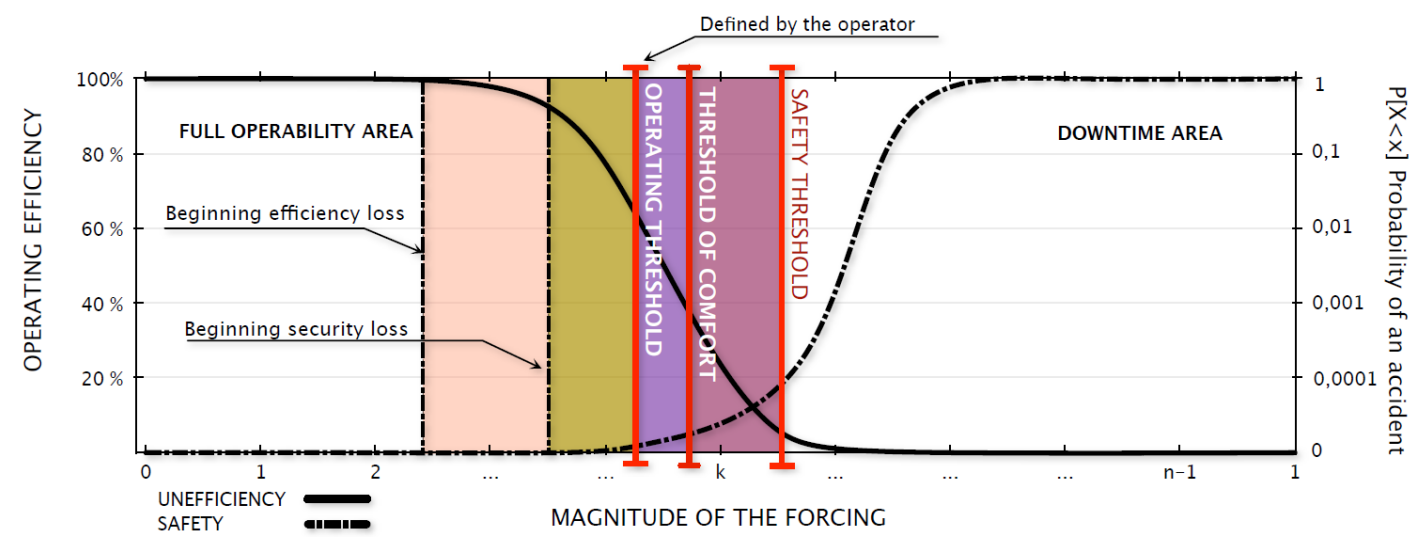

Figure 6. Theoretical relation between the magnitude of the forcing and the operation efficiency. Reproduced from Molina (2015) [27].

In the latest contribution from the WG 115 of the Maritime Navigation Commission (PIANC, 2012 [19]) an effort was made to relate the magnitude of the predominant agents and the oscillations of the free surface with the movements of the vessel and its consequences on the productivity or target performance. This new approach differs from other previous reports that expressed the threshold simply as a maximum tolerable range or wave amplitude. The need of a detailed characterization of the boundary conditions at each dock and anchorage is highlighted once more, in order to be able to implement a probabilistic vision in terms of a downtime analysis similar to the one outlined in Figure 7 (ROM 0.0-01, 2001 [1]). In this figure, the operative threshold it is related to the number of stoppages and the duration of each stoppage along service lifetime. Therefore, it can also be seen as technical and economic criteria for the design, management and operation of a terminal, associated with the desired level of service, KPIs (Key Performance Indicator) and KPOs (Key Performance Objectives).

From the point of view of the authors of the present paper, generic thresholds are not likely to be directly applicable to every operational activity, vessel or dock. On the contrary, the concept of an operational threshold is a value that each operator should define according to the boundary conditions defined in Section 2, which are specific for each dock or anchorage and ship status. The latter includes, not only the coercion scheme (mooring plan), but also the variations due to the cargo status, as fully loaded ships behave differently from ships without cargo. It also needs to be defined according to each particular requirement, as an operation could be stopped for being economically unprofitable, for a poor efficiency or because it compromises the integrity of the cargo, the handling means, the vessel, the environment or the safety of the personnel.

The threshold approach remains today one of the axes of port design, a common point of view of management and exploitation. However, as set out in Section 2, it presents a series of limitations associated with the mono-parametric simplification of a multi-dimensional problem, as well as derived from not considering explicitly the movements of the vessel and the variability of the limit conditions in relation to the particular site, handling means and human factor. 


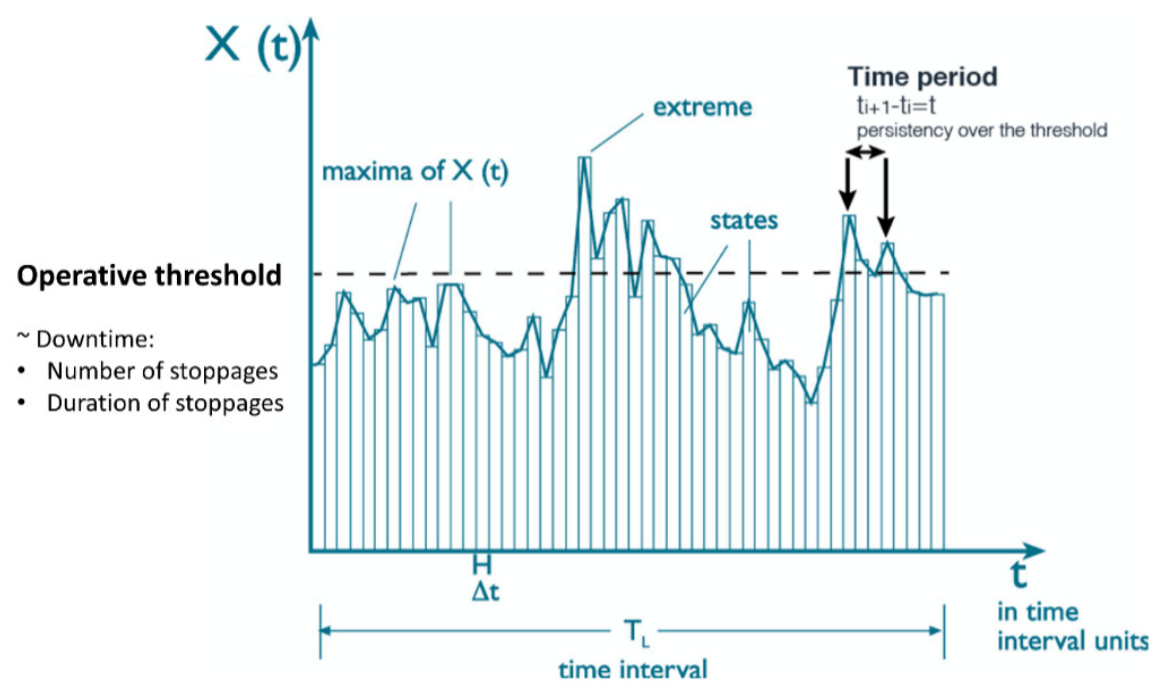

Figure 7. Exceedance of an operational threshold for a variable $X$ within the framework of climate states. Every single bar represents the ergodic and stationary interval of a climate state $(\Delta t)$. Adapted from ROM 0.0 (2001) [1].

\subsection{Conditioned Thresholding}

Conditioned thresholding offers the possibility of introducing more than one variable in the evaluation of the operability. Each variable is analyzed independently following a mono-parametric approach. To accomplish this, limit conditions are established for each of the variables. Afterwards, the individual operational windows are calculated with a downtime analysis in the time domain depending on the minimal operational duration, as show in Figure 8. The actual operational window is finally calculated as the intersection of the operational windows from the different variables. In other words, it is assumed that the operation can be carried out if all variables are below their operational limit during, at least, the minimal operational duration.

This method can be seen as an evolution of the mono-parametric approach, as it allows the inclusion of as many variables as desired in the operability analysis. However, its main limitation is that each variable is considered to be independently regarding operability. This is not a realistic approximation, especially when dealing with met-ocean agents, which usually shows relations of dependence between them. In addition, settling operative limit conditions to each of the independent variables can be really challenging as well as inappropriate when focusing on met-ocean agents: as shown in Section 3.3, their concomitant interaction encourages the shift from the mono-parametric concept of thresholds to the n-parametric identification of climate states provoking downtimes. 


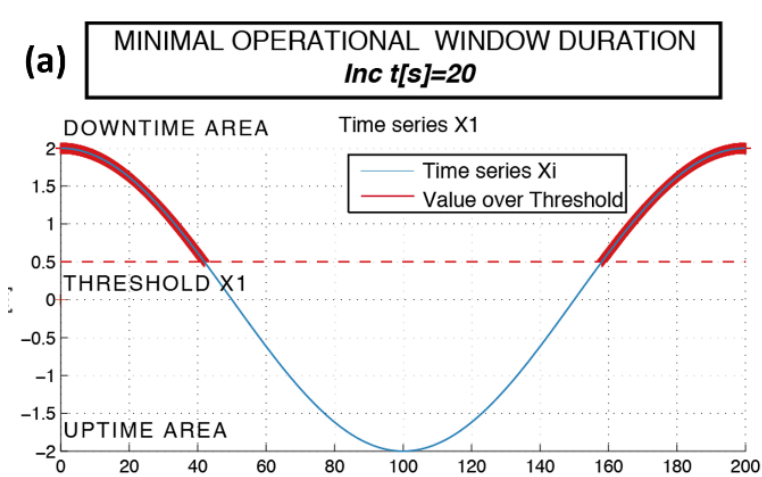

[s]

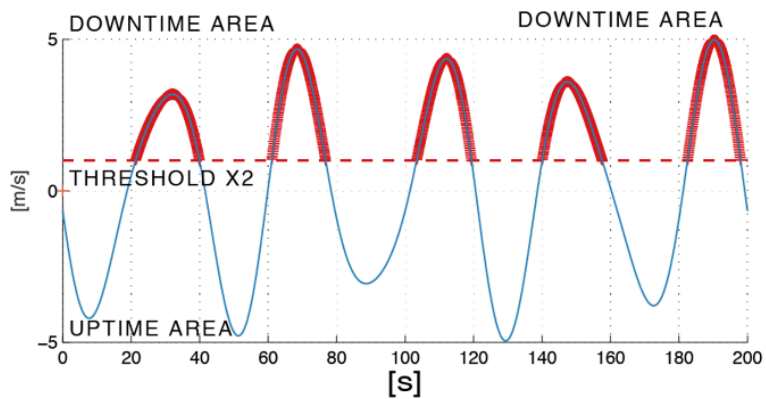

OPERATIONAL WINDOWS. Time intervals $=1$

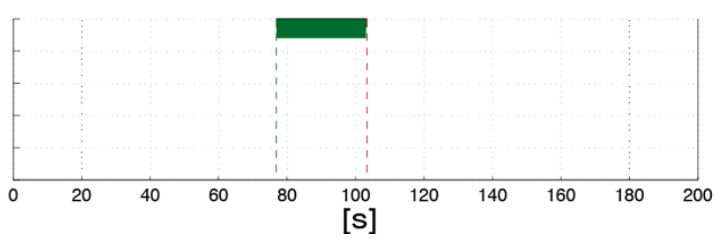

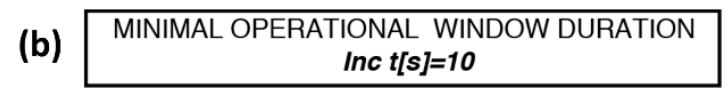

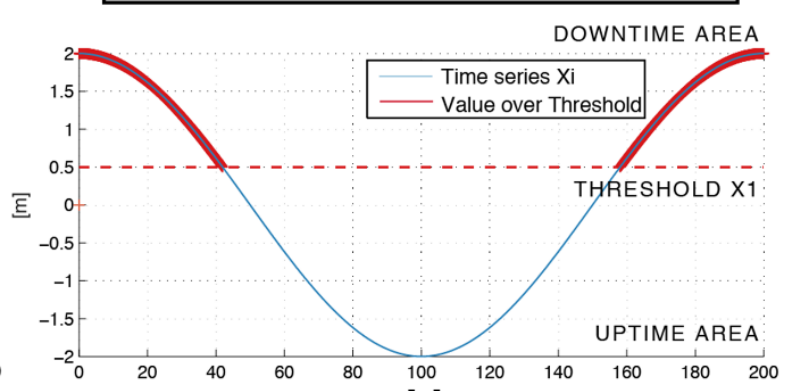

[s]

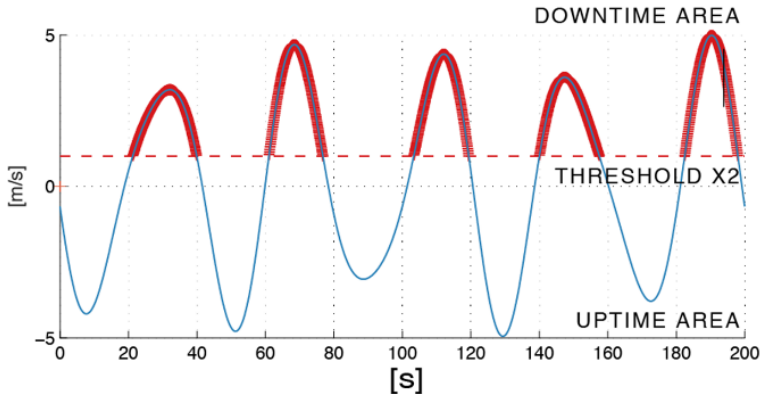

OPERATIONAL WINDOWS. Time intervals $=3$

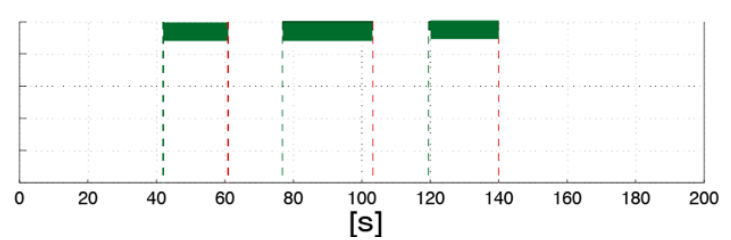

Figure 8. Scheme of an operational analysis based on conditioned thresholding on two variables. Notice that the operational windows depends on the minimal operational duration and on having both variables below their own limit condition. (a) Results for a minimal operational window of $20 \mathrm{~s}$; (b) Results for a minimal operational window of $10 \mathrm{~s}$. Own elaboration.

\subsection{N-dimensional Thresholding}

As an evolution from the conditioned thresholding, n-dimensional thresholding allows for considering as many variables as desired without assuming that they are independent regarding operability. Indeed, there are certain concomitant combinations of forcing agents that are able to provoke downtimes without being associated with a high mono-parametric level. For example, as mentioned in Section 2.3, infra-gravitational waves can affect the operability of large vessels even when they are associated with a low wave high. Similarly, the combination of wind load and wave agitation can cause downtimes when acting together with lower values than when they are acting alone (Díaz-Hernández et al., 2015 [55]).

For carrying out an n-dimensional thresholding, data mining techniques and selection algorithms are usually applied, as they allow for extracting patterns and basic information from a usually high amount of data with high dimensionality. Some examples of $\mathrm{n}$-dimensional classification and selection algorithms are Self Organized Maps (SOM, Kohonen, 2001 [56]), Vector Quantization with Conscience mechanism (VQC, Kohonen, 1988 [57]), K-Means Algorithms and Maximum Dissimilarity Algorithms (Camus et al., 2011 [58]). Following different approaches, these techniques compute a set of M clusters or centroids, each of them representative of a group of data. SOM present the advantage of being able to space the results in a $2 \mathrm{D}$ regular lattice, facilitating the visual interpretation of the results.

In this case the input data are typically composed of independent time series from the n-variables, which need to be firstly normalized in order to synchronize the time records. The objective of this methodology is to summarize this amount of information to a reduced number of weather states 
representative of the whole data and associated with different operability levels. The main limitation of this approach is its dependency on extensive onsite monitoring of met-ocean agents and the dynamic response of each vessel.

\subsection{Inference Models}

Given the large number of variables that can take part in the characterization of the operability, inference models might be a recommendable choice, as they allow for combining as many variables and casuistic as desired with, at least, one target variable such as the efficiency of the operation. In this way, the complex interplay among agents can be directly linked and compared to the serviceability levels established by port and terminal managers.

In line with the n-dimensional thresholding, this approach can be especially dependent on extensive onsite monitoring of met-ocean agents and the dynamic response of each vessel. Not only this, as shown in Figure 9, the mooring scheme, ship parameters, type of cargo, load distribution and handling equipment need to be considered for enhancing the accuracy of the models. Also, during the (un)loading operation, the targets variables, i.e. levels of efficiency, reliability, safety and comfort, need to be monitored, either quantitatively as a sensing device input or qualitatively as user consultation.

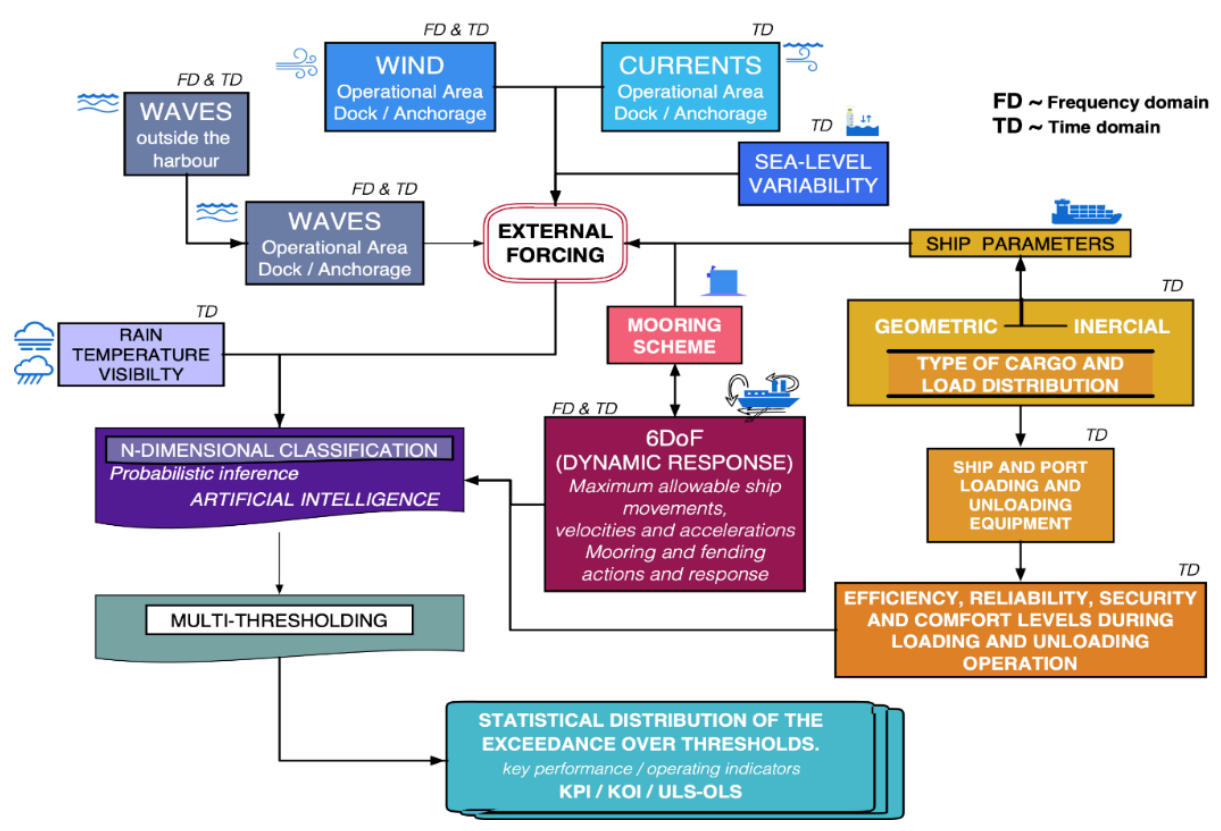

Figure 9. Scheme of an inference model based on an n-dimensional classification of forcing agents and the ship response. Own elaboration.

The inference model to predict key performance or operating indicators can be built using different techniques. For example, an n-dimensional classification can be carried out as explained in Section 3.3 and connected with the surveyed serviceability levels by means of an interpolation strategy. In Camus et al. (2011) [59] this methodology was applied for downscaling wave climate to coastal areas, using a nonlinear interpolation technique based on Radial Basis Functions (RBFs). Other possible techniques for developing the inference model are supervised or automatic artificial intelligence techniques such as Bayesian Networks (see OpenBUGS, Lunn et al., 2009 [60]), or Neural Networks (Hagan et al., 1996 [61], Abhishek et al., 2012 [62], Gómez et al., 2016 [63]). Finally, Monte Carlo simulations (Benedicto et al., 2018 [64]) might also be of interest.

\subsection{User-Oriented Thresholding Tools}

As discussed throughout the article, the characterization of operability in docks and anchorages is a complex challenge with a high degree of particularization. Port spaces are typically heterogeneous, 
with different uses, typologies, handling means, ships types, drafts, etc. In addition, these spatial domains are highly subjected to local interaction between met-ocean agents, infrastructure and the fleet. Addressing the vulnerability of a port and its activities against met-ocean agents is analyzing in detail each of its elements and subsystems, as well as the interaction between them. Therefore, an approach based on general guidelines, such as tabulated thresholds, might not be accurate enough in most cases.

From the point of view of port management, another possible methodology to address this challenge is through decision-making tools that combine the concept of geo-probability (Campos et al., 2019 [10]) together with allowing terminal operators to define their own threshold according to their experience and needs. In this line, the OPPE is developing within the SAMOA2 project (2019-2021) an Atlas of Operational Vulnerability (AOV) for different Spanish ports. It will be part of the CMA (Cuadro de Mando Ambiental, translated from Spanish as Environmental Dashboard), a responsive web platform designed to aid in port management and control by providing information about met-ocean variables in port areas. This tool was successfully implemented in the Port Authority Bahía de Algeciras (Spain) and the OPPE in 2016 within the Project I+D+i Algeciras SafePort [65] or SAMPA II and, up to date, 471 port users were subscribed.

On the one hand, the geospatial component has been considered in this tool through the high-resolution characterization of several met-ocean variables (wave agitation, wind and currents) at the port's AOIs. Dividing a port into AOIs offers a spatial structure in which substantiating management decisions by accumulating experience and systematizing the analysis of operational vulnerabilities. Also, the gradual increase on monitoring records of operational variables and met-ocean agents would allow for enhancing the accuracy of predictive models.

On the other hand, this spatial structure is shared with the potential users of the port by means of an interactive and simple navigation tool based on a Web-GIS viewer. As shown in Figure 10, by activating different pop-ups, users can access to the general metadata of the AOI and to a $72 \mathrm{~h}$ forecast of its main met-ocean variables. They are also given the possibility to modify the default threshold values for each of the met-ocean variables at the AOI. In this way, an operational ad-hoc map of vulnerability is provided in qualitative terms through a traffic light code: red (high vulnerability), yellow (mean vulnerability), and green (low vulnerability).

Apart from this tool, the users from CMA were offered the possibility of defining alerts inside different ports, based on overcoming met-ocean forecasts such as wind velocity and wave agitation. In this case, these variables are not always linked to high-resolution models. Each port establishes default thresholds for the met-ocean variables based on PIANC (2012) [19] and ROM 2.0 (2011) [18]. However, as a similarity with the $\mathrm{AOV}$, users can also customize their own thresholds.

After surveying and filtering the information from CMA, so far, a total of 79 users from 17 Spanish State Ports have been counted to customize their own thresholds. Algeciras and Barcelona were the ports with more customizing users, with a number of 27 and 15 users, respectively. Every user is allowed to customize their met-ocean thresholds in different POIs (Point of Operational Interest, which are either the centroid of an AOI or any other points of relevance, regarding operability, in which met-ocean forecasting is provided), either maritime or terrestrial, inside the port area. As a result, 94 POIs were customized with wave agitation thresholds and 139 POIs with wind velocity thresholds. This information, summarized in Figure 11a, highlights that not every user agrees with the default thresholds and prefers to adapt them to their particular requirements. In ports such as Algeciras, users tend to customize more wind thresholds than agitation thresholds, although more research is needed to clarify the reasons. Note that Algeciras is the only port wherein the AOV has been installed so far and, since its launch in 2016, just about $6 \%$ of the users have customized their thresholds. Probably further dissemination is needed to fully exploit the possibilities of the tool. Considering that there are 50 maritime AOIs in Algeciras and 63 terrestrial AOIs, it can be stated that customized thresholds are focused just on certain AOIs and that users managing the whole port are mainly employing the ones by default. Finally, the results on Figure 11a also reveal the interest of the port community in this kind 
of tools, although in many ports barely one POI is offered inside CMA. This situation, nevertheless, will change after the conclusion of project SAMOA2, as most Spanish State Ports will considerably enhance the spatial resolution of met-ocean predictions inside ports, as well as their accuracy.

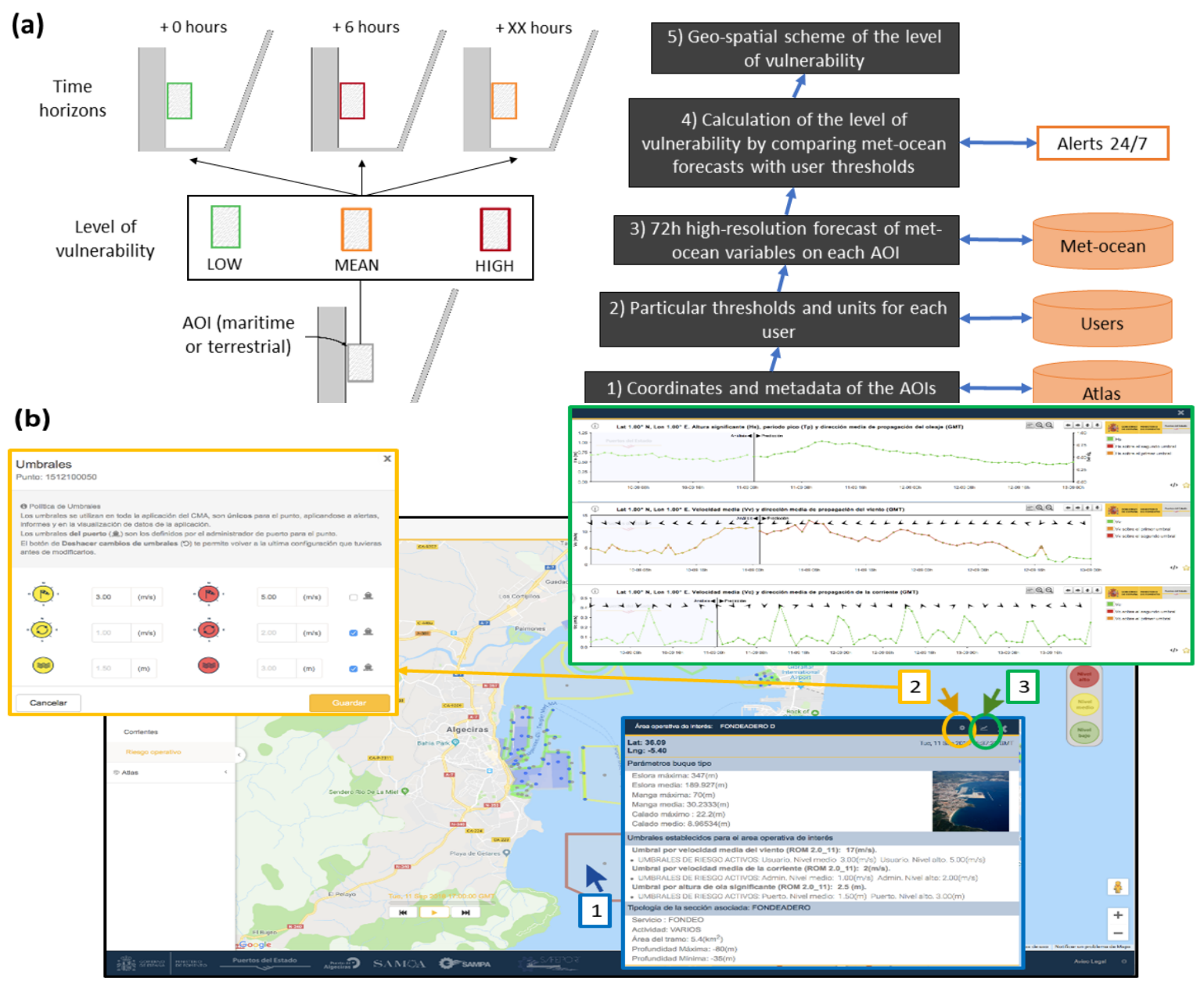

Figure 10. (a) Conceptual scheme for the development of the Atlas of Operational Vulnerability (AOV) of the Meteorological and Oceanographic Support Systems for the Port Authorities (SAMOA 2 project);.(b) AOV for the Port Authority of Algeciras (Spain), in which the vulnerability of each Area of Operational Interest (AOI) is represented by a traffic light color code together with a forecast time line up to $72 \mathrm{~h}$. (1) By selecting an AOI, a pop-up is displayed with its metadata (identifier, typology, activity, quantitative aspects and characteristics of the fleet), an image and information about the default or user-customized thresholds. (2) By selecting the corresponding icon within pop-up 1, a new pop-up is displayed allowing the user to customize the thresholds and units associated with that AOI. (3) By selecting the corresponding icon within pop-up 1, $72 \mathrm{~h}$ forecast time series of main met-ocean variables at the AOI are offered (wind, wave agitation and currents), in which the units and color code are particularized for each user. Own elaboration from CMA (https://cma.puertos.es/). 
(a)
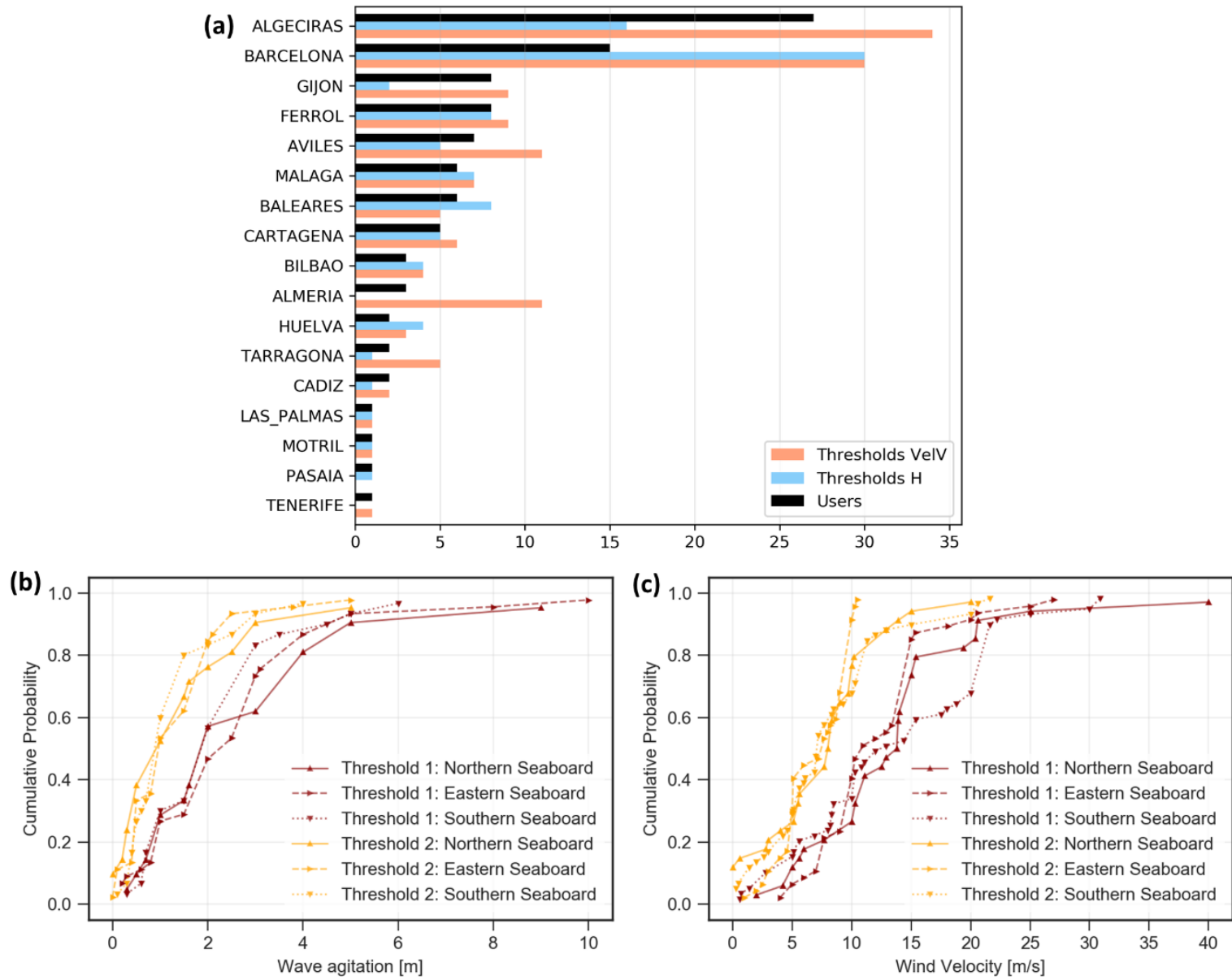

Figure 11. (a) Number of CMA users with customized thresholds for different Spanish State Ports, together with the total Points of Operational Interest (POIs) with customized thresholds for agitation $(\mathrm{H})$ and wind velocity (VelV) inside the port (notice that users can customize as many POIs as available at each port); (b) Experimental Cumulative Density Function (CDF) of customized agitation thresholds for the Spanish State Ports sorted by seaboards. Threshold1 is related to a high vulnerability and Threshold2 to a mean vulnerability; (c) Experimental CDF of customized wind velocity thresholds for the Spanish State Ports sorted by seaboards. Threshold1 is related to a high vulnerability and Threshold2 to a mean vulnerability. Own elaboration, based on CMA database.

Figure 11b,c represent, respectively, the experimental CDF (Cumulative Density Function) of the wave agitation and wind velocity thresholds customized by CMA users. They define two thresholds regarding their perception of vulnerability: Threshold 1 (in red) is associated with a high level of vulnerability, whereas Threshold 2 (in orange) is linked to a mean level. The results are sorted by seaboards:

- The northern seaboard includes the Spanish State Ports of Avilés, Bilbao, Ferrol, Gijón and Pasaia.

- The eastern seaboard includes the Spanish State Ports of Baleares, Barcelona, Cartagena and Tarragona.

- The southern seaboard includes the Spanish State Ports of Algeciras, Almería, Cádiz, Huelva, Málaga and Motril.

The results show the wide range of thresholds defined by the users, evidencing experimentally the particular perception of this concept. It is noticeable that, despite some authors stating an operative limit for cranes at $\mathrm{v}(\mathrm{m} / \mathrm{s})=25$ (Jensen et al., 1990 [28], PIANC, 2012 [19]), customized wind thresholds are much lower in most cases. This is not in line with the fact that they are indeed capable of operating with wind velocities above the operative limit threshold of $v(\mathrm{~m} / \mathrm{s})=25$. More research is needed to 
identify the reasons for this conservative trend regarding wind velocity limits. As a hypothesis, this can be due to the fact that only the quasi-static wind component is forecast and, thus, the variable component (gusts), which is indeed the component closely related to downtimes, is expected to be higher. In any case, this opens the debate on the adequacy of the met-ocean descriptors, as the commonly-employed statistic descriptors (for example at hourly spans) are not fully representative of actions such as the perseverance and intensity of each gust. The latter requires the wind characterization at a high resolution both in the time domain and the frequency domain, with monitoring rates and analysis in the range of seconds rather than minutes or hours.

The trends of Threshold 2 for the different seaboards are quite similar, except for the upper tail. For Threshold 1, wave agitation values over $60 \%$ cumulative probability are higher in the northern seaboard and lower in the southern seaboard, with the eastern seaboard values between them. This might be explained regarding the more severe wave climate in the North of Spain, which makes the port community more used to rough wave conditions during operations and, therefore, their perception of vulnerability is likely to be linked to higher wave agitation values in comparison with other seaboards. This trend is also noticeable for wind velocity between the northern and the eastern seaboards. However, the southern seaboard presents the highest thresholds for the middle-up results. This might be due to the influencing weight of the port of Algeciras in the overall results: being exposed to the strong winds of the Gibraltar's strait, their perception of vulnerability linked to wind velocity is likely to be less conservative. Note that the population sample is still small for analyzing regional trends regarding the perception of the vulnerability in port areas, but it is clarified with respect to the singularity of the threshold's concept. Customized values are above and below the ones recommended in PIANC (2012) [19] or ROM 2.0 (2011) [18], although more information is still needed to explain these custom values, especially at the upper and lower tails.

\section{Conclusions}

The concept of operational threshold is nowadays facing a review process. The digitalization of ports' environments and the introduction of the Industry 4.0 within the logistic chain have brought to the port community new management tools (PMS, PCS, TOS) and new monitoring strategies (artificial vision, IoT, met-ocean, etc.). The availability of the information allows for an enhancement in optimization of logistics processes, the Business Intelligence (BI) and the decision-making tools, for example, by defining when an (un)loading operation should be stopped and under what criteria. The port system is reaching such a level of development that nowadays it is possible to relate the boundary conditions of the (un)loading operation of a berthed ship with the different serviceability levels: efficiency, reliability, safety and comfort.

In this paper, the concept of operability in relation to (un)loading operations at docks and anchorages is addressed. The study is extensible to other ship-based operations such as bunkering or the embarking and disembarking of passengers and vehicles. Despite being only slightly covered in the literature, in comparison with the ship operability regarding seakeeping and maneuverability, the efficiency and safety of (un)loading operations is one of the key issues in port management, largely affecting terminals' revenue. Even the justification of the port structural investments largely depends on being able to estimate potential downtimes caused by the interaction with met-ocean agents. While most approaches up to now suggest connecting operability with the magnitude of mono-parametric met-ocean thresholds, it is each ship and its dynamic response the main sea-side actors that are directly related to the decision of stopping an operation, something for which there is not an agreed criterion. Indeed, nowadays this decision is eminently taken by subjective criteria from Port Captaincy, the Port Authority, the ship captain, the terminal operator, or the stevedores, each of them with different perceptions, responsibilities and efficiency objectives. Therefore, a common perception of the operational vulnerability in the port community is needed. In this way, it would be possible to shift to systematic and objective decision-making strategies based on agreed criteria, capable of addressing the particular stakeholders' needs and peculiarities of each operation. Main 
challenges and factors involved in the characterization of the operability on berthed ships were discussed, pointing out the broad casuistic and the many singularities faced. This suggests a particular approach for each dock rather than an approach based on generic thresholds. To accomplish this, an accurate characterization of the met-ocean agents at each AOI is required, both in the time domain and in the frequency domain and considering the concomitant relationships between them. That is, increase the met-ocean agents monitoring at docks and improve forecasting with high resolution numerical modeling. Indeed, the operability of a berthed ship is closely related to the excitation and dynamic response in the frequency domain. Wave period or mean/max intensity, together with gust's persistency, needs to be included as key factors connecting forcing agents with efficiency, reliability, safety and comfort of operations. Met-ocean characterization need to be accomplished together with the onsite monitoring of the movements of the vessel during operations. Other factors of relevance to be considered are the ship's geometric and inertial parameters and the typology and configuration of the dock's infrastructures, system of mooring lines and fenders. The type of goods, their arrangement within the ship and the handling means also plays and important role. Finally, the human factor is also involved in the performance of a (un)loading operation, which can be dependent, for example, on the operator's skills or on the singular perception of the vulnerability. Main approaches and methodologies for the characterization and calculation of operability in docks and anchorages were also discussed. On the one hand, we have identified the need for widening the mono-parametric threshold approach to conditioned and n-dimensional thresholding approaches and inference models capable of addressing the high number of variables and factors involved and the relations between them. On the other hand, the perception of vulnerability was proven to be subjective, by taking into account the surveyed experience from a user-oriented decision-tool disseminated within the Spanish port's community. This tool allows for the customization of met-ocean thresholds for activating personal alerts based on high-resolution met-ocean forecasts. As shown in Figure 11, the range of variation of these custom thresholds is significative. Although the population sample is still small, it opens a near future discussion on the adequacy of generic thresholds. Custom wind thresholds defined by the users tends to be, so far, significantly more conservative than the ones presented in PIANC (2012) [19] or ROM 2.0 (2011) [18]. This fact is not in line with the experience in port exploitation, as port managers perceive that operations are carried out, in many cases, above the thresholds established in these references. This apparent contradiction points out the importance of counting on the user experience, as their perception of vulnerability and efficiency is likely to differs from the general thresholds from the recommendations. Their experience also might indicate the unsuitability of certain met-ocean forecast parameters regarding a straight comparison with these general thresholds. For example, as stated in Section 2.3, wind gusts (maximum wind intensity in relation to its average value at different heights) are not yet provided in the forecasting models. Thus, the aforementioned conservative trend of the users regarding wind thresholds might be due to the fact that the actual wind velocity affecting their operations is higher than the forecast mean value. It needs to be highlighted that projects such as SAMPA, I+D+i Algeciras SafePort or SAMOA2 have opened the door to the redefinition of operative thresholds in port activities. The Spanish port's community have now (or will have at the end of the project SAMOA2) the support of high-resolution systems for measuring and forecasting met-ocean variables at different AOIs inside most State Ports. This information is publicly accessible and is transmitted to port's users through the aforementioned user-oriented tool CMA. This tool allows users to customize their perception of vulnerability on each port location according to their particular requirements and experience on each operation or activity. In this way, the efficiency, reliability, safety and comfort of port operations can be enhanced through a more accurate knowledge of the operational requirements.

As a final conclusion, the operative threshold needs to evolve towards the combination of factors that force the unfulfillment of the serviceability levels established by port and terminal managers. Downtimes are produced when an operation cannot be carried out as a result of a loss of service of the port infrastructure, when the (un)loading operation is not efficient or when the activity carried out by 
operators and users is not safe or has a low level of comfort. There are three main elements related to the concept of operative threshold: (1) The operational facilities and the infrastructure where the activity is developed; (2) the vessel as the main actor and (3) the forcing met-ocean agents interacting with the operation. The combination of these three factors is specific and unique to each location and operation, as so they are their operative thresholds. In Figure 12, the author's vision about the present and the future in the calculation of the operability on berthed ships in the Spanish port system is summarized.

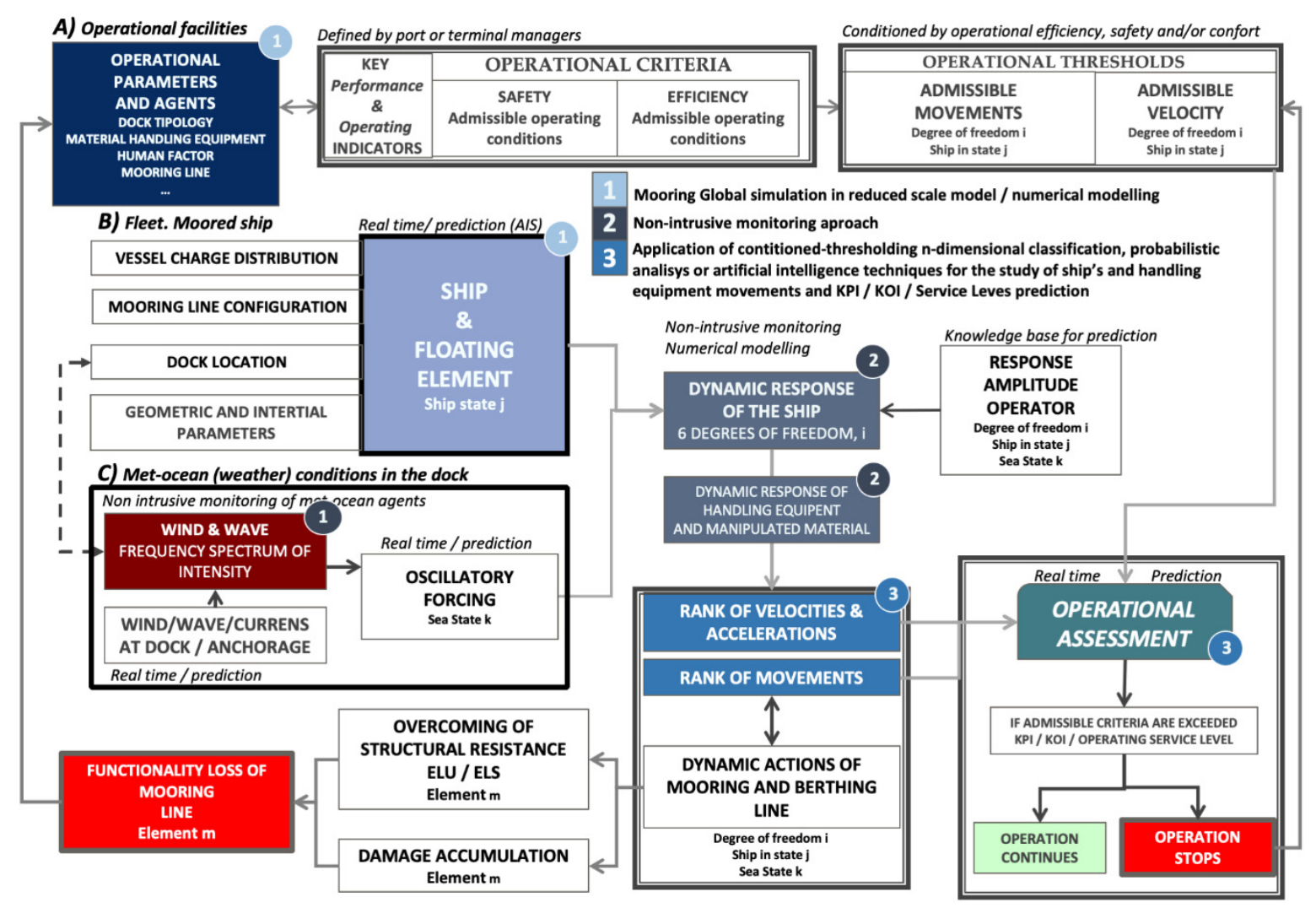

Figure 12. Summary of the present and future strategy for assessing operability on berthed ships proposed by the authors. Own elaboration.

Author Contributions: Conceptualization: R.M.-S., F.J.d.1.S. and E.Á.-F. Methodology: R.M.-S., Á.C., F.J.d.1.S., P.R.-R. and A.C.-O. Validation: R.M.-S. Formal analysis: Á.C. and R.M.-S. Investigation: R.M.-S. and Á.C. Resources: S.P.-R. Writing-original draft preparation: Á.C. and R.M.-S. Writing—review and editing: R.M.-S., Á.C., M.d.A., F.J.d.1.S., P.R.-R., S.P.-R., A.C.-O. and E.Á.-F. Supervision: R.M.-S., F.J.d.1.S., M.d.A. and A.C.-O. Project administration: R.M.-S., P.R.-R. and M.d.A. Funding acquisition: R.M.-S., F.J.d.1.S., E.Á.-F. All authors have read and agreed to the published version of the manuscript.

Funding: This research received no external funding.

Acknowledgments: The authors are indebted to Oritia \& Boreas S.L. for their leadership in the Project I+D+i Algeciras SafePort and to IHCantabria as team members of the working group of the same project.

Conflicts of Interest: The authors declare no conflict of interest.

\section{References}

1. Puertos del Estado. ROM 0.0-01. General Procedure and Requirements in the Design of Harbor and Maritime Structures. PART I.; Puertos del Estado: Madrid, Spain, 2001.

2. Molina, R.; Rodríguez-Rubio, P.; Carmona, M.Á.; De los Santos, F.J. Guía Para La Aplicación de Un Sistema de Gestión de Riesgos Océano-Meteorológicos En El Ámbito Portuario y Su Evaluación: Certificación de Puerto Seguro Océano-Meteorológico; Autoridad Portuaria Bahía de Algeciras: Cádiz, Spain, 2017. 
3. Gómez, R.; Molina, R.; Castillo, C.; Rodríguez, I.; López, J.D. Conceptos y Herramientas Probabilísticas Para El Cálculo Del Riesgo En El Ámbito Portuario; Puertos del Estado: Madrid, Spain, 2018.

4. Sierra, J.P.; Genius, A.; Lionello, P.; Mestres, M.; Mösso, C.; Marzo, L. Modelling the impact of climate change on harbour operability: The barcelona port case study. Ocean Eng. 2017, 141, 64-78. [CrossRef]

5. Camus, P.; Tomás, A.; Díaz-Hernández, G.; Rodríguez, B.; Izaguirre, C.; Losada, I.J. Probabilistic assessment of port operation downtimes under climate change. Coast. Eng. 2019, 147, 12-24. [CrossRef]

6. Gracia, V.; Sierra, J.P.; Gómez, M.; Pedrol, M.; Sampé, S.; García-León, M.; Gironella, X. Assessing the impact of sea level rise on port operability using LiDAR-derived digital elevation models. Remote Sens. Environ. 2019, 232, 111318-1-111318-13. [CrossRef]

7. Campos, Á.; García-Valdecasas, J.M.; Molina, R.; Castillo, C.; Álvarez-Fanjul, E.; Staneva, J. Addressing long-term operational risk management in port docks under climate change scenarios-A Spanish case study. Water 2019, 11, 2153. [CrossRef]

8. Newman, J.N. The Theory of Ship Motions; Academic Press: New York, NY, USA, 1978; pp. 221-283.

9. Lloyd, A.R.J.M. Seakeeping: Ship Behaviour in Rough Weather; E. Horwood: New York, NY, USA, 1989.

10. Mata-Álvarez-Santullano, F.; Souto-Iglesias, A. Stability, safety and operability of small fishing vessels. Ocean Eng. 2014, 79, 81-91. [CrossRef]

11. Manderbacka, T.; Themelis, N.; Bačkalov, I.; Boulougouris, E.; Eliopoulou, E.; Hashimoto, H.; Konovessis, D.; Leguen, J.F.; Míguez González, M.; Rodríguez, C.A.; et al. An overview of the current research on stability of ships and ocean vehicles: The STAB2018 perspective. Ocean Eng. 2019, 186, 106090. [CrossRef]

12. Sariöz, K.; Sariöz, E. Habitability assessment of passenger vessels based on ISO criteria. In Marine Technology and SNAME News; Society of Naval Architects and Marine Engineers: Manila, Philippines, 2005; pp. 43-51.

13. Tezdogan, T.; Incecik, A.; Turan, O. Operability assessment of high speed passenger ships based on human comfort criteria. Ocean Eng. 2014, 89, 32-52. [CrossRef]

14. Cabrerizo-Morales, M.Á.; Molina, R.; De los Santos, F.; Camarero, A. Optimization of operationality thresholds using a maneuver simulator. case study: Floating gate at Campamento shipyard. In Proceedings of the 33rd International Conference on Coastal Engineering; ASCE, Santander, Spain, 2-6 July 2012.

15. Cabrerizo-Morales, M.Á.; Molina, R.; Valdecasas, J.G.; Abanades, J.; Pérez-Rojas, L. Mooring Line Load Thresholds Definition Based on Impulsive Load Analysis during Wind Turbine+gbf Instalation. H2020 DemoGravi3. In Proceedings of the 7th International Conference on the Application of Physical Modelling to Port and Coastal Protection, Santander, Spain, 22-26 May 2018.

16. Guachamin Acero, W.; Li, L.; Gao, Z.; Moan, T. Methodology for Assessment of the Operational Limits and Operability of Marine Operations. Ocean Eng. 2016, 125, 308-327. [CrossRef]

17. PIANC MarCom WG 24. Criteria for Movements of Moored Ships in Harbours-A Practical Guide. Rept. Working Group No. 24; Permanent Technical. 1995. Available online: https://www.pianc.org/publications/marcom/ criteria-for-movements-of-moored-ships-in-harbours-a-practical-guide (accessed on 4 April 2020).

18. Puertos del Estado. ROM 2.0-11. Design and Construction of Berthing E Mooring Structures (Volume I and II); Puertos del Estado: Madrid, Spain, 2012.

19. PIANC MarCom Working Group 115. Criteria for the (Un)Loading of Container Vessels. 2012. Available online: https://www.pianc.org/publications/marcom/criteria-for-the-unloading-of-container-vessels (accessed on 4 April 2020).

20. Goedhart, G. Criteria for (Un)-Loading Container Ships; 2010.

21. Bruun, P. Port Engineering; Gulf Publishing Company: Houston, TX, USA, 1990.

22. Gaythwaite, J.W. Design of Marine Facilities for Berthing, Mooring and Repair of Vessels; Van Nostrand Reinhold: Nueva York, NY, USA, 1990.

23. Thoresen, C.A. Port Designers Handbook 2nd Edition; Thomas Telford Publishing: London, UK, 2010.

24. Slinn, P.J.B. Effect of ship movement on container handling rates. Dock Harb. Auth. 1979, 60, 117-120.

25. Moes, H.; Terblanche, L. Motion criteria for the efficient (Un)loading of container vessels. In Port Infrastructure Seminar; Delft University of Technology: Delft, Holland, 2010.

26. Rosa-Santos, P.; Taveira-Pinto, F.; Veloso-Gomes, F. Experimental evaluation of the tension mooring effect on the response of moored ships. Coast. Eng. 2014, 85, 60-71. [CrossRef]

27. Molina, R. Caracterización de La Agitación Local y La Respuesta Oscilatoria de Un Buque Mediante El Uso de Técnicas de Visión Artificial. Aplicación Al Análisis de Los Umbrales Operativos En Líneas de Atraque y Amarre. Ph.D. Thesis, Universidad Politécnica de Madrid, Madrid, Spain, 2015. 
28. Jensen, O.J.; Viggosson, G.; Thomsen, J.; Bjordal, S.; Lundgren, J. Criteria for ship movements in harbours. In Proceedings of the 22nd International Conference on Coastal Engineering, Delft, The Netherlands, 2-6 July 1990; pp. 3074-3087.

29. CEM. Coastal Engineering Manual; CERC: Vicksburg, MS, USA, 2005.

30. Díaz-Hernández, G.; Tomás, A.; Rodríguez, B.; López-Lara, J.; de los Santos, F.J.; Losada, I.J. Numerical ship-wave generation, propagation and agitation analysis, related with harbor downtime management. In Proceedings of the 34th PIANC World Congress, Panama City, Panama, 7-11 May 2018.

31. Bowers, E. Harbour resonance due to set-down beneath wave groups. J. Fluid Mech. 1977, 79, 71-92. [CrossRef]

32. Bellotti, G. Transient response of harbours to long waves under resonance conditions. Coast. Eng. 2007, 54, 680-693. [CrossRef]

33. González-Marco, D.; Sierra, J.P.; Fernández de Ybarra, O.; Sánchez-Arcilla, A. Implications of long waves in harbor management: The gijón port case study. Ocean Coast. Manag. 2008, 51, 180-201. [CrossRef]

34. Dean, R.G.; Dalrymple, R.A. Water Wave Mechanics for Engineers and Scientists; World Scientific Publishing Company Incorporated: Hackensack, NJ, USA, 1991; Volume 2.

35. OCIMF. Mooring Equipment Guidelines, 3rd ed.; MEG3: Londres, Inglaterra, 2008.

36. Álvarez-Fanjul, E.; García-Sotillo, M.; Pérez-Gómez, B.; García-Valdecasas, J.M.; Pérez-Rubio, S.; Ruiz Gil de la Serna, M.I.; de Alfonso, M.; Rodríguez-Dapena, A.; Martínez-Marco, I.; Luna, Y.; et al. Impacto del proyecto SAMOA en las AA.PP: Hacia un SAMOA 2. In Proceedings of the XV Jornadas Españolas de Ingeniería de Costas y Puertos, Universitat Politècnica de València, Málaga, Spain, 8-9 May 2019.

37. Rodríguez, B.; Díaz-Hernández, G.; López-Lara, J.; Tomás, A.; Álvarez de Eulate, M.F.; Medina, R.; Álvarez-Fanjul, E.; Pérez-Gómez, B.; García-Valdecasas, J.M. Proyecto SAMOA-2: Módulos de agitación, ondas largas y rebase, descripción general. In Proceedings of the XV Jornadas Españolas de Ingeniería de Costas y Puertos, Universitat Politècnica de València:, Malaga, Spain, 8-9 May 2019.

38. Terrés-Nicoli, J.M.; Mans, C.; García-Valdecasas, J.; Molina, R.; Álvarez-Fanjul, E. Predicción de viento de alta resolución en zonas portuarias en el marco del proyecto SAMOA2. In Proceedings of the XV Jornadas Españolas de Ingeniería de Costas y Puertos, Universitat Politècnica de València, Malaga, Spain, 8-9 May 2019.

39. Espino, M.; Cerralbo, P.; Mestres, M.; Gómez, J.; Grifoll, M.; García-Sotillo, M.; Álvarez-Fanjul, E.; Sánchez-Arcilla, A. Predicciones de corrientes marinas de alta resolución anidadas en CMEMS para el desarrollo de productos de valor añadido en los puertos españoles. In Proceedings of the XV Jornadas Españolas de Ingeniería de Costas y Puertos, Universitat Politècnica de València, Malaga, Spain, 8-9 May 2019.

40. PROAS-Port Risk Optimized Advanced System. Available online: https://innovacion.apba.es/proas-portrisk-optimized-advanced-system/ (accessed on 6 March 2020).

41. D'Hont, I.E. Port and terminal construction design rules and practical experience. In Proceedings of the 12th International Harbour Congress, Antwerp, Belgium, 22-27 September 1999; pp. 19-48.

42. Satoh, H.; Shiraishi, S.; Yoneyama, H. Analysis of the allowable ship motions for container ships and ferries. Annu. J. Civ. Eng. Ocean JSCE 2003, 19, 643-648.

43. Castillo, C.; Castillo, E.; Fernández-Canteli, A.; Gómez, R.; Molina, R. Rainflow analysis in coastal engineering using switching second order markov models. Appl. Math. Model. 2012, 36, 4286-4303. [CrossRef]

44. Gomez, R.; Molina, R.; Castillo, E.; Castillo, C. Wave analysis using rainflow information. Ocean. Eng. IEEE J. 2013, 38, 12-24. [CrossRef]

45. Cabrerizo, M.A.; Molina, R.; Matutano, C.; Llana, A. Control of Porosity, Reflection and Transmisión Coefficients Using Polymeric Porous Media and Their Application in Testing Physical Models; UPC: Barcelona, Spain, 2010.

46. Cabrerizo, M.A.; Molina, R.; Rodriguez, A.; Polimon, C.; Eguiagaray, M. Simulación global operativa de operaciones de fondeo de cimentaciones de gravedad offshore (GBFs). Aplicación al fondeo de dos torres meteorológicas en Moray Firth e Inch Cape (Escocia). In Proceedings of the XIII Jornadas Españolas de Ingeniería de Costas y Puertos, Universitat Politècnica de València, Avilés, Spain, 24-25 June 2015.

47. Cabrerizo, M.A.; Sánchez, M.; López, J.D.; Camarero, A. A non intrusive approach to floating structures simulation: Small scale real-. time caisson monitoring \& control system (SREC-MOCOS). In Proceedings of the 4th International Conference on the Application of Physical Modelling to Port and Coastal Protection, Universiteit Gent, Ghent, Belgium, 17-20 September 2012; pp. 351-353. 
48. Pérez-Arribas, F.; Zamora, R.; Pérez-Rojas, L.; Freiria, J. A quick estimation of seakeeping characteristics on fishing vessels. In Proceedings of the IMAM 2005-Maritime Transportation and Exploitation of Ocean and Coastal Resources, Lisboa, Portugal, 26-30 September 2005.

49. Johanning, L.; Smith, G.H.; Wolfram, J. Measurements of static and dynamic mooring line damping and their importance for floating WEC devices. Ocean Eng. 2007, 34, 1918-1934. [CrossRef]

50. Malheiros, P.L.; Rosa-Santos, P.J.; Moreira, A.P.; Da Costa, P.G.; Gomes, F.V.; Pinto, F.T. Robust and real-time motion capture of rigid bodies based on stereoscopic vision. In Proceedings of the 3rd International Conference on Integrity, Reliability and Failure, Porto, Portugal, 20-24 July 2009.

51. Fujarra, A.; Gonçalves, R.; Fonseca, R.; Siewert, K.; Martins, J. Optical motion capture as a techinique for measuring the water wave elevation. In Proceedings of the 4th International Workshop on Applied Offshore Hydrodynamics (IWAOH), Rio de Janeiro, Brazil, 2-4 December 2009.

52. Figuero, A.; Sande, J.; Peña, E.; Alvarellos, A.; Rabuñal, J.R.; Maciñeira, E. Operational thresholds of moored ships at the oil terminal of inner port of a coruña (Spain). Ocean Eng. 2019, 172, 599-613. [CrossRef]

53. Velsink, H. Principles of Integrated Port Planning; Bulleting of PIANC; PIANC: Brussels, Belgium, 1987; Volume 56.

54. Puertos del Estado. ROM 0.2-90. Actions in the Design of Maritime Structures; Recomendaciones para obras marítimas; Puertos del Estado-Ministerio de Fomento: Madrid, Spain, 1990.

55. Diaz-Hernandez, G.; Mendez, F.J.; Losada, I.J.; Camus, P.; Medina, R. A nearshore long-term infragravity wave analysis for open harbours. Coast. Eng. 2015, 97, 78-90. [CrossRef]

56. Kohonen, T. Self-Organizing Maps; Springer: Berlin/Heidelberg, Germany, 2001.

57. Kohonen, T. An introduction to neural computing. Neural Netw. 1988, 1, 3-16. [CrossRef]

58. Camus, P.; Mendez, F.J.; Medina, R.; Cofiño, A.S. Analysis of clustering and selection algorithms for the study of multivariate wave climate. Coast. Eng. 2011, 58, 453-462. [CrossRef]

59. Camus, P.; Mendez, F.J.; Medina, R. A hybrid efficient method to downscale wave climate to coastal areas. Coast. Eng. 2011, 58, 851-862. [CrossRef]

60. Lunn, D.; Spiegelhalter, D.; Thomas, A.; Best, N. The BUGS project: Evolution, critique and future directions. Stat. Med. 2009, 28, 3049-3067. [CrossRef] [PubMed]

61. Hagan, M.T.; Demuth, H.B.; Beale, M.H. Neural Network Design; PWS Pub. Co.: Boston, MA, USA, 1996.

62. Abhishek, K.; Singh, M.P.; Ghosh, S.; Anand, A. Weather forecasting model using artificial neural network. Procedia Technol. 2012, 4, 311-318. [CrossRef]

63. Gómez, R.; Molina Sánchez, R.; Camarero, A.; De los Santos, F.J. Development of a terminal operability forecasting system: Analysis of the effects that wind generates over quay cranes performance. Coast. Eng. Proc. 2014, 1, 16. [CrossRef]

64. Benedicto, M.I.; García-Morales, R.M.; Marino, J.; De Los Santos, F. A decision support tool for port planning based on monte carlo simulation. In Proceedings of the 2018 Winter Simulation Conference (WSC), Gothenburg, Sweden, 9-12 December 2018; pp. 2885-2896.

65. SafePORT-Gestión Avanzada de Riesgos Océano-Meteorológicos. Available online: https://innovacion. apba.es/safeport/ (accessed on 28 March 2020).

(C) 2020 by the authors. Licensee MDPI, Basel, Switzerland. This article is an open access article distributed under the terms and conditions of the Creative Commons Attribution (CC BY) license (http://creativecommons.org/licenses/by/4.0/). 